\title{
Post-encephalitic Parkinsonism: current experience
}

\author{
D A VID R A L, CARL SCHOLTZ, AND MICHAELSWASH \\ From the Departments of Neurology and Neuropathology, The London Hospital and \\ The London Hospital Medical College, London
}

SUMMARY The diagnosis of post-encephalitic Parkinsonism is rarely entertained today. In this paper we discuss eight recent patients, six of whom presented in the last 20 years, that conform to the diagnosis of encephalitis lethargica. The clinical features by which the diagnosis may be made are defined so that a contemporary definition of this disorder may be attained.

Encephalitis lethargica occurred in epidemic proportion in Europe and other countries between 1915 and $1930 . .^{2}$ It was an acute illness, usually accompanied by fever, characterised by somnolence with ophthalmoplegia and sometimes with other focal neurological disturbances such as hemiplegia or aphasia. In a second form of the disease hyperkinesis, chorea and myoclonus, and inversion of the sleep rhythm occurred and in a third type an acute Parkinsonian syndrome, sometimes with a catatonia-like stupor, was observed. ${ }^{1}$ Many other symptoms were recorded during the epidemic and, despite contemporary reviews ${ }^{1-5}$ it is difficult to be certain, in the absence of a specific diagnostic test, that these apparently diverse neurological syndromes were variations of the same entity. Wilson in particular expressed this view: "There is reason to believe the encephalitis is not identical at all times and in all localities, and that it may cover states of dissimilar aetiology."11

In the years since encephalitis lethargica ceased to be endemic it has generally been held that postencephalitic Parkinsonism is an uncommon disorder. However, even before the epidemic, sporadic cases similar to encephalitis lethargica occurred ${ }^{1-3}$ and, in recent years, there have been several isolated reports of cases thought to be examples of newly-acquired post-encephalitic Parkinsonism. ${ }^{613}$ These reports lend some support to the suggestion that idiopathic Parkinsonism itself might be caused by encephalitis, perhaps acquired years earlier. ${ }^{14}$ Indeed, Eadie, Sutherland and

Address for reprint requests: Dr M Swash, The London Hospital, London E1 1BB, UK.

Accepted 22 May 1981
Doherty ${ }^{15}$ found that $13 \%$ of a series of 83 Parkinsonian patients in Australia gave a history consistent with previous encephalitis lethargica, and a further $10 \%$ had experienced other encephalitides. Only one of 50 non-Parkinsonian patients gave such a history. However, this apparent association has not been the experience of others. ${ }^{16-18}$ Before the epidemic of encephalitis lethargica, Parkinsonism was very rare before the age of 40 years. ${ }^{2}$ Willige, ${ }^{19}$ found reports of only 20 cases beginning before the age of 30 in the 60 years 8 before 1910. Nonetheless, it seems important to recognise that a form of encephalitis still exists in which Parkinsonism occurs as a residual deficit, $\rightleftharpoons$ since only when the features of this modern postencephalitic extrapyramidal disease have been defined can it be recognised, and investigated.

\section{Patients}

Case 1 (PT 335618)

In 1961 this 20-year-old woman became acutely ill with headaches, fever, drowsiness, and vomiting. During this illness, which lasted several weeks, her left arm and leg became weak and numb. Investigations including a right carotid angiogram, an air encephalogram and CSF examination were normal. She improved at first but during the next three years a pronounced dystonic bradykinesia developed with prominent cogwheel rigidity. There was a slight resting Parkinsonian tremor, more marked in the leftsided limbs. The tendon reflexes were normal and both plantar responses were flexor. There was no sensory impairment. By 1967 her face and her right arm and leg were severely affected. At this stage the EEG showed irregular theta and delta waves, and sharp elements bilaterally. Wilson's disease was excluded, and she had never been treated with neuroleptic drugs. She failed to respond to treatment with anticholinergic 
drugs and levodopa and by 1970 she was wheelchairbound and unable to look after herself without help.

\section{Case 2 (VM 733224)}

In 1976 this 29-year-old man was admitted to another hospital after a bout of "influenza," an illness which consisted of headache, fever, malaise and cough of a few days duration. Two weeks later, while still in hospital he complained of a general feeling of "restlessness within myself" which was relieved by walking. Mental concentration was impaired. He was treated with diazepam but became progressively slowed and catatonic. He was transferred to a psychiatric hospital where it was thought that he was depersonalised and electroconvulsive therapy was started. Neuroleptic drugs were not used. However, there was no improvement after two treatments and he was transferred to The London Hospital. On admission marked Parkinsonian features were observed. He was strikingly akinetic with a fixed expression and there was cogwheel rigidity and bradykinesia of all limbs. There was a resting distal Parkinsonian tremor in both arms, which disappeared during movement. Tremor was less evident in the legs. The tendon reflexes were brisk, but the plantar responses were flexor. There was no other neurological signs. Despite the akinetic expression and posture there was pronounced akathisia, so that he could not sit in one place for more than a few minutes. Investigations, including a CSF examination and an isotope brain scan were normal. He showed no response to levodopa but improved with bromocryptine $60 \mathrm{mg}$ daily and by June 1976 his bradykinesia was much less marked. Blood and CSF titres for antibodies against influenza $A$ and $B$, parainfluenza, adenovirus, measles, mumps and mumps V, H simplex, varicella zoster, coxiella burneti, psittacosis-LGV and mycoplasma pneumoniae were all within the normal range $(1: 32)$.

\section{Case 3 (PS 49639)}

This 50-year-old man was admitted to hospital in 1973 two weeks after the onset of his illness. Soon after arriving in Majorca on holiday he had become unrousable and was admitted to hospital. At that stage he was in coma with constricted pupils, eyes deviated to the right, and corticospinal signs in all four limbs. Treatment with dexamethasone $12 \mathrm{mg} /$ day was begun after a lumbar puncture had shown CSF containing $0.80 \mathrm{mg}$ protein/1 and 25 white cells/ $\mathrm{mm}^{3}$, predominantly mononuclears. The blood serology, ESR and echoencephalogram were normal. $\mathrm{He}$ improved slightly during the next three days, becoming stuporose with larger and reactive pupils. $\mathrm{He}$ was then transferred to the Atkinson Morley's Hospital. At this time his level of consciousness varied from a state of stupor, from which he was rousable only by deep painful stimuli, and a quiet awake akinetic state in which he lay with eyes open. He could obey commands but initiated no activity. His face was expressionless and there was paresis of upward gaze and of conjugate gaze to the left: downward gaze was normal. There was a marked dysarthria, with cogwheel tone and a slight Parkinsonian resting tremor in the arms. All limbs were weak and both plantar responses were extensor. The EEG was diffusely abnormal with a large amount of irregular theta waveforms and occasional delta activity. The CSF contained 4 white cells $/ \mathrm{mm}^{3}$. CT scan of the head was normal. Virological studies, including titres of antibodies to influenza $A$ and $B$, parainfluenza, mumps and $\mathrm{V}$ virus and to mycoplasma pneumoniae were normal in both blood and CSF. After a twoweek period of observation, during which there was no improvement, he was treated with Sinemet 110, 1 tablet twice daily increasing to Sinement 275, 1 tablet four times daily after 2 weeks. Within 3 weeks of starting he could sit out of bed and talk coherently, although his speech was still slow and slurred. When reexamined at that time his pupils were midsize and did not respond to light, although they responded to accommodation. Pursuit gaze movements were slowed and interrupted by jerky saccades. Voluntary upward gaze was impaired but doll's-head eye movements were full. His facies was immobile and there was marked akinesia of the limbs, with cogwheel rigidity and resting tremor in both arms. The right plantar response was flexor and the left equivocal.

\section{Case 4 (AM 509075)}

This 44-year-old man was admitted to The London Hospital in 1969 two weeks after the onset of an illness consisting of persistent inappropriate laughing, followed by fever, drowsiness and difficulty dressing. These symptoms continued for two days, when he had a convulsion and was admitted to another hospital. At that time he was noted to be "drowsy with slow movements." The CSF was normal. After several days his mood changed to one of aggression and it was noted that he had difficulty looking up and down. There was no history of administration of neuroleptic drugs. On admission he was impassive but could be aroused to inappropriate jocosity. There was bilateral ptosis. On gaze fixation he tended to look tonically downwards, with exaggeration of resting divergence. Lateral gaze was full but there was paralysis of voluntary reflex upward gaze. Optokinetic nystagmus was absent in all directions. He was akinetic in all limbs and the right arm showed slight plastic rigidity. There was no tremor. Both plantar responses were flexor. There was released palmar grasping. The EEG showed bilateral diffuse high voltage delta activity with some theta components. The CSF and an air encephalogram were normal. His mental state improved slowly during several weeks. When reassessed in 1976 voluntary gaze upwards and downwards were absent although lateral gaze was normal. Convergence and accommodation were impaired. He remained impassive and was still inclined to laugh inappropriately during conversation. Bradykinesia was still present in all limbs but tone was normal and there was no tremor. 
Case 5 (MT 402835)

This woman was admitted to The London Hospital in 1968 , aged 43 years, for investigation of a change in personality during the previous four years. She had been a woman of intellectual distinction, but had gradually become withdrawn. It had been thought that she was depressed but she had not responded to treatment with imipramine and benzodiazepines. She had not been treated with phenothiazines or other neuroleptic drugs. At times she was excessively talkative but at others she was quiet and tearful. About one month before admission she gradually developed difficulty speaking and she was admitted to a local hospital. At that time she was drowsy and seemed depressed, and she appeared to be experiencing auditory hallucinations. In the next few days she had several generalised convulsions, became increasingly dysphasic and developed weakness of her right side. She gradually deteriorated over a two-week period, becoming mute and unresponsive, and was transferred to The London Hospital. On examination at this time she was conscious but mute. She was akinetic for long periods but occasionally she threw herself from side to side, or made swimming movements with her arms. The right sided tendon jerks were brisker than the left and the right plantar response was extensor. A few weeks later cogwheel rigidity with some tremor developed in all limbs especially on the right. CSF examination revealed a raised protein $(0.6 \mathrm{~g} / \mathrm{l})$ and cell count (white cells $20 / \mathrm{cm}^{3}$ ). An air encephalogram and left carotid angiogram were normal. Serial EEG studies during several months showed frequent high voltage spike activity with phase reversal in the left central electrodes. The later records were generally disorganised but of progressively lower voltage and these showed less marked left-sided predominance. Viral antibody titres to mumps, adenovirus, measles and $\mathrm{H}$ Simplex viruses in CSF and blood were normal. After about three months her mental state began to improve so that she became alert and responsive although some expressive dysphasia persisted and she remained rather inaccessible to all except her closest friends. The corticospinal and extrapyramidal abnormalities persisted.

Case 6 (JH 39945/25)

This man developed Parkinsonism in 1953 at the age of 43 years, following encephalitis. The latter illness consisted of fever, seizures, and drowsiness, with corticospinal signs and akinesia, but without gaze palsies. The CSF showed a raised protein and a lymphocytosis during this illness. Viral antibody titres were not investigated. Oculo-gyric crises were a feature of the recovery phase of this illness, and akinetic Parkinsonism with dysarthria emerged at this time. His Parkinsonian syndrome improved slightly with benztropine and amantadine treatment. Levodopa induced dyskinetic axial and oro-facial movements which proved intolerable. In 1976 his Parkinsonism was moderately severe. It was characterised by impaired speech, a flexed posture and pronounced bradykinesia of all limbs. There was generalised cogwheel rigidity, with tremor of Parkinsonian type.

\section{Case 7 ( $B W$ 345420)}

In 1965 during a period of only a few months, this woman, then aged 40 years, developed tremor of the hands, especially on the right, with bradykinesia of the face and lid retraction. During this time she experienced recurrent oculogyric crises, especially if emotionally stressed. There was no history of administration of neuroleptic drugs, or of encephalitis. Her condition remained stable at first and she declined treatment but five years later she found that she was beginning to deteriorate. A marked improvement occurred with levodopa treatment $(750 \mathrm{mg}$ three times a day) although she continued to complain of oculogyric crises, occurring several times monthly. However, this improvement was not maintained, and eight years later (aged 53 years) she was severely disabled and unresponsive to levodopa, bromocryptine or anticholinergic drugs. There was a severe tremor of the hands often with a choreic quality, together with marked cogwheel rigidity in all limbs. The left plantar response was extensor, and the right flexor. She could walk only a few steps, with tendencies to both festination and retropulsion. Speech and swallowing were both abnormal and there was a severe abnormality of respiration consisting of an irregular respiratory rhythm, with interpolated gasps and grunts. She was unable to co-ordinate pharyngeal, oral and facial movements with respiration so that a mechanical airway obstruction developed. External ocular movements were full, but slowed, with saccadic interruption of slow following movements. Oculogyric crises were observed. She deteriorated further, and died of bronchopneumonia aged 56 years. After necropsy examination of the brain showed almost total loss of neurones in the substantia nigra and locus coeruleus (fig 1). No Lewy bodies were seen in the few remaining neurones in the substantia nigra, but neurofibrillary tangles were seen in many of these

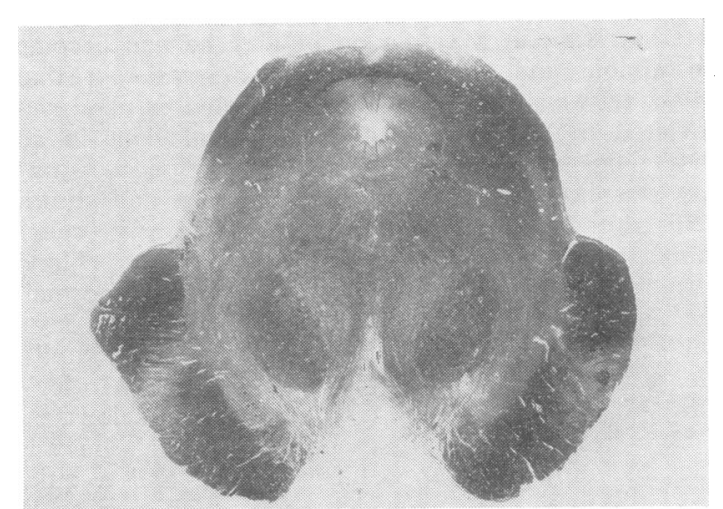

Fig 1 Section of the midbrain showing almost total loss of neurones in the substantia nigra. PTAH. 


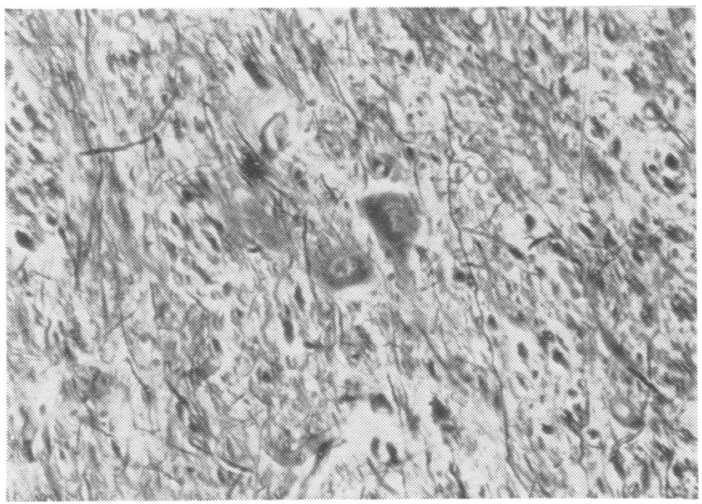

Fig 2 Section showing neurofibrillary tangles in neurones of the substantia nigra. Gless and Marsland $\times 175$.

neurones (fig 2), and to a lesser degree in the dentate nucleus, corpus striatum and cortical neurones. No Alzheimer plaques were found. Small glial scars were found in the substantia nigra. There was slight demyelinisation of the middle zone of both cerebral peduncles. The spinal cord was normal.

\section{Case 8 (TS $7357 / 56)$}

In 1945, while in the Middle East, this man had a febrile illness in which oculogyric crises occurred. His eyes would suddenly deviate upwards for a minute or so; he had difficulty moving or talking during these episodes. The illness otherwise consisted of fever and drowsiness. In 1949 when he was aged 32 years he was found to have Parkinsonism, with asymmetrical tremor and rigidity, and slight bradykinesia. He was treated with stramonium for several years, and began benzhexol in 1960. By 1970, when he was aged 53 years, he had become disabled. He walked with rigid legs, taking tiny shuffling steps. There was a resting tremor of the right hand, and he could no longer play the piano or harp. Although formerly employed as an electrician he had been able to manage only light duties as a porter for some years, and was no longer able to write. His speech had become quiet and slurred during the previous five years and he had developed some difficulty swallowing. His mouth was always open, so that he could not control his salivation. There was a tendency for him to perform repeated drumming movements with his hands. Breathing was often irregular. No oculogyric crises had occurred in recent years. Treatment with Sinemet 110 one tablet twice daily resulted in only slight improvement. This could not be increased because it induced dystonia. In 1980 examination showed a gaunt man with a mild kyphosis. Memory and orientation were intact, but there was marked Parkinsonism, with tremor of the tongue and of both hands, and with cogwheel rigidity in the arms and legs. His gait was slow, but retropulsion and festination were not observed. Conjugate upward gaze was slightly impaired,

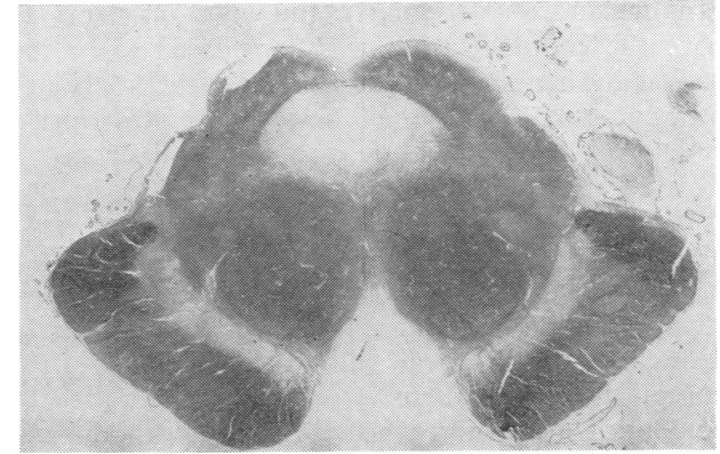

Fig 3 Midbrain section showing pallor of the substantia nigra which has been severely depleted of neurones. $P T A H$.

and the facies was impassive. The right plantar response was extensor but the left was flexor. A CT scan showed slight enlargement of the lateral and third ventricles, but normal sulci. Subsequently he died, and examination of the brain after necropsy showed severe neuronal loss in the substantia nigra (fig 3). The remaining neurones in this region showed prominent neurofibrillary tangles, but no Lewy bodies were seen. Glial scars were prominent in the substantia nigra. In the cerebral cortex neurofibrillary tangles and Alzheimer plaques were absent. The spinal cord was normal.

\section{Discussion}

These eight patients display a diverse range of clinical features which are, nonetheless, similar to those which characterised encephalitis lethargica during the pandemic nearly 60 years ago. An encephalitic phase was not always noted in cases observed in the pandemic, but this was the prodrome from which the more distinctive Parkinsonian features developed in all but two (cases 5 and 7) of our patients. The disease was acquired more recently than 1960 in six of the eight patients. The "peculiar lethargic sleepy state . . . one minute in deep coma, the next answering questions intelligently and again, slipping back into deep sleep" ${ }^{20}$ was a feature of the encephalitic illness in two of our patients (cases 3 and 4). This feature, from which the name encephalitis lethargica arose, was prominent in the initial stages of the classical illness. ${ }^{1-4}$ In later epidemics florid positive motor symptoms (tics, chorea, mania and akathisia) were far more frequently found ${ }^{2}$ as in two of our patients (cases 2 and 4). This constellation of symptoms confounded any compact definition of the larger body of cases until von Economo's unifying concept prevailed. ${ }^{1}$ The basal 
ganglia, more particularly the substantia nigra, bore the brunt of what was considered to be invasion by a neurotropic virus. ${ }^{21}$ Of the survivors of the acute phase of the illness, the great majority developed Parkinsonian features to some degree. ${ }^{16}$ This major diagnostic feature of the illness occurred in all our patients. Psychiatric features, including personality changes, psychosis and a profound akinetic state easily mistaken for catatonia, characterised three of our patients (cases 2, 4 and 5). This accords with the neuropsychiatric complications frequently reported in the early epidemics. ${ }^{22}$ During the period in which encephalitis lethargica was common focal motor abnormalities such as hyperreflexia, weakness of corticospinal type, or extensor plantar responses, were features which served to distinguish "symptomatic" cases from idiopathic Parkinson's disease. ${ }^{22}$ Sensory or visual field disturbances, however, were uncommon. Other features of our cases typical of encephalitis lethargica were oculogyric crises (cases 6, 7 and 8), evidence of involvement of the mesencephalon such as pupillary changes or gaze palsies (cases 3 and 4), ${ }^{6}$ respiratory disturbances (cases 7 and 8), and the early age of onset (cases 1 , $2,4,5,6,7$, and 8). Pathological examination of cases 7 and 8 showed extensive bilateral loss of neurones from the entire substantia nigra and locus coeruleus. Where neurones remained they were filled with neurofibrillary material. Lewy bodies were not observed. Small glial scars were seen in the substantia nigra in both cases. There was slight demyelination of the midportion of the cerebral peduncles in both cases. Neurofibrillary change was also observed more widely distributed in the brain stem, dentate nuclei and corpus striatum. In case 7 neurofibrillary tangles were also seen in cortical neurones in the absence of neuritic plaques. These pathological findings are typical of post-encephalitic Parkinsonism. The small glial scars in the substantia nigra are confirmatory evidence of a previous encephalitic illness. ${ }^{20}$

Despite advances in diagnostic techniques since 1920 no definite serological or biochemical markers for encephalitis lethargica have been discovered. The diagnosis therefore depends on recognition of its clinical features. However, the latter are heterogeneous and it is therefore worth considering whether it is possible to define the clinical features of encephalitis lethargica itself. In particular, the disorder must be separated from idiopathic Parkinson's disease and from the larger group of acute viral and post-viral encephalitis in which signs of involvement of the extrapyramidal system may be a feature. ${ }^{725}$ Most recent reports have been concerned with this latter form of post-encephalitic Parkinsonism. Bojinov ${ }^{12}$ reporting 17 cases of encephalitis complicated by Parkinsonism occurring recently in Bulgaria, noted that the Parkinsonian syndrome can be mild or severe. The disorder was fatal in $30 \%$ of his cases but in the remainder partial or complete recovery ensued. The pathological features of the encephalitis in Bojinov's cases ${ }^{12}$ differed from those described in the pandemic of encephalitis lethargica, consisting of a brain stem polioencephalitis with symmetrical haemorrhagic necrosis of the substantia nigra. Attempts to isolate a virus were unsuccessful ${ }^{13}$ although in other sporadic reports of post-encephalitic Parkinsonism the disorder has been associated with serological evidence of infection by poliomyelitis, ${ }^{23}$ Coxsackie B2 $^{24}$ and Echo viruses. ${ }^{13}$ In most of these cases Parkinsonism has been transient, no residual deficit remaining three months after the encephalitic phase. In our cases Parkinsonism was chronic and severe. Nonetheless, these observations support the concept that Parkinsonism may complicate the encephalitis resulting from infection with a number of different viruses, in addition to encephalitis lethargica itself.

In order to delineate encephalitis lethargica and its extrapyramidal complications from postencephalitic Parkinsonism in the broader sense of an extrapyramidal complication of a variety of different types of encephalitis the specific clinical features of the former must be recognised (table).

\section{Table Clinical features of encephalitis lethargica}

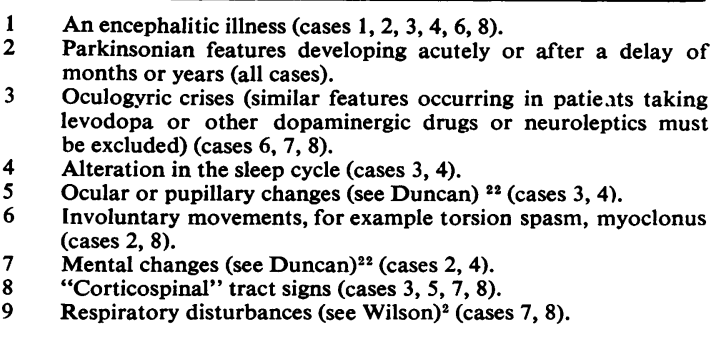

These features must, clearly, include an encephalitic illness and the development of Parkinsonian signs either acutely, or after an interval. The latter may be as long as several months, or even years. ${ }^{124}$ However, the diagnosis depends on more specific features than simply the development of post-encephalitic Parkinsonism. Oculogyric crises are a major feature of encephalitis lethargica, as 
in cases 6,7 , and 8 , but similar ocular abnormalities occurring in patients taking levodopa or other dopaminergic drugs, or neuroleptic medication, must be excluded. Indeed, the diagnosis should not be considered in a patient known to have been treated with neuroleptics. Other features are less specific since they consist of clinical findings similar to those found in patients with a variety of degenerative disorders, with cerebral vascular disease, or with tumours of the basal ganglia or brain stem.

During the pandemic of encephalitis lethargica it was noted that some patients presented with Parkinsonism and oculogyric crises, together with several of the minor features noted in the table, but without a clear-cut encephalitic illness, and this may still be the case today, although the diagnosis is then very difficult. Of our eight patients, three had oculogyric crises and were thus typical of encephalitis lethargica. In most of the remainder, there were marked signs of upper brain stem involvement together with sleepiness, restlessness, respiratory disturbances and mental changes similar to those described during the pandemic of encephalitis lethargica and we suggest that these patients also suffered from the latter disorder. In three of these patients viral studies were performed, but these were all negative.

One further point concerns the definition of encephalitis. In a review of the diagnosis and outcome of encephalitis Kennard and Swash ${ }^{25}$ defined encephalitis as an illness, usually of rapid onset and progression, with signs of diffuse or multifocal involvement of the central nervous system, and of inflammation of the brain, other causes having been excluded. In most of their patients the encephalitic illness occurred during or shortly after a systemic viral infection, but, in some the encephalitis occurred without an evident associated systemic viral infection.

Our clinical observations suggest that a form of Parkinsonism with clinical features similar to those recorded during the pandemic of encephalitis lethargica is recognisable today. Other cases, less typical than those we have discussed above, may well fit into the concepts of encephalitis lethargica and post-encephalitic Parkinsonism as we have tried to define them, but recognition of these syndromes is difficult. A reappraisal, in prospective studies, may lead to definition of this group of disorders by epidemiological and virological techniques.

We thank our colleagues Dr R Henson and Dr A Ridley in the Neurological Unit at The London
Hospital, for allowing us access to their notes. Case 3 is reported by kind permission of $\mathrm{Dr} J$ Meadows, Consultant Neurologist, Atkinson Morley's Hospital.

\section{References}

1 von Economo C. Encephalitis lethargica. Its sequelae and treatment. Trans Newman KD. London: Oxford University Press 1931.

2 Wilson SAK. Epidemic encephalitis. In: Wilson SAK, Neurology. London: Edward Arnold 1940. 99-145.

3 Hall AJ. Epidemic encephalitis. New York: William Wood and Co 1924.

4 Parsons AC. Report of inquiry into afterhistories of persons attacked by encephalitis lethargica. Reports on public health and medical subjects, No 49. Ministry of Health, London: His Majesty's Stationery Office 1928.

5 Dimsdaye $\mathbf{H}$. Changes in Parkinson syndrome in the 20th century. Quart J Med 1946; 15:155-70.

6 Bickerstaff ER, Cloake PCP. Mesencephalitis and rhombencephalitis. Br Med J 1951; ii:77-81.

7 Nielson JM. Complications of encephalitis of von Economo type. Bull Los Angeles Neurol Assoc 1953; 18:84-90.

8 Brewis EG. Recent experience of encephalitis in childhood. Br Med J 1954; i:1298-302.

9 Espir MLE, Spalding JMK. Three recent cases of encephalitis lethargica. Br Med J 1956; 1141-4.

10 Hunter R, Jones $M$. Acute lethargica-type encephalitis. Lancet 1966; ii:1023-4.

11 Herishanu J, Noah Z. An acute encephalitic Parkinsonian syndrome. Europ Neurol 1973; 10: 117-24.

12 Bojinov S. Encephalitis with acute Parkinsonian syndrome and bilateral inflammatory necrosis of the substantia nigra. J Neurol Sci 1971; 12:383415.

13 Bojinov S. Current acute Parkinsonian encephalitis (in Bulgarian with an English summary). Sofia: Medicini i Sizhutura 1975.

14 Schwab RS, Doshay LJ, Garland H, Bradshaw P, Garvey E, and Crawford B. Shift to older age distribution in Parkinsonism: a report on 1000 patients covering the past decade from three centers. Neurol (Minneap) 1956; 6:783-90.

15 Eadie MJ, Sutherland JM, Doherty. Encephalitis in the aetiology of Parkinsonism in Australia. Arch Neurol 1965; 12:240-5.

16 Duvoisin RC, Yahr MD. Encephalitis and Parkinsonism. Arch Neurol 1965; 12:227-39.

17 Hoehn MM. The epidemiology of Parkinsonism. In: de Ajuriagueffa $\mathbf{J}$ and Gauthier $\mathrm{G}$, eds. Monoamines nojaux gris centraux et syndrome de Parkinson. Geneva: Georg et Cie 1971; 281-300.

18 Marttila RJ, Rinne UK. Epidemiology of Parkinson's disease in Finland. Acta Neurol Scand 1976; 53:81-102. 
19 Willige $H$. Ueber paralysis agitans in jugendlichen Alter. Z Neurol Psychiat 1911; 4:520-87.

20 Greenfield JG. Encephalomyelitis and the clinical pathologist. J Clin Path 1956; 9:1-11.

21 Encephalitis lethargica. Its nature, symptoms and treatment. London: His Majesty's Stationery Office 1926.

22 Duncan AG. The sequelae of encephalitis lethargica. Brain 1924; 47:76-95.

23 Thieffry S. Enterovirus (Poliomyelite, Coxsackie,
ECHO) et maladies du systeme nerveux. Revision critique et experience personelle. Rev Neurol 1963; 105:753-76.

24 Poser CM, Huwley CJ, Poland JD. Paraencephalitic Parkinsonism. Report of an acute case due to coxsackie virus type $\mathrm{B} 2$ and re-examination of the aetiologic concepts of postencephalitic Parkinsonism. Acta Neurol Scand 1969; 45:199-215.

25 Kennard C, Swash M. Acute viral encephalitis: its diagnosis and outcome. Brain 1981; 104:129143. 